\title{
Um esforço em rede para compreensão do turismo em tempos de pandemia
}

Eloise Silveira Botelho

Universidade Federal do Estado do Rio de Janeiro

(UNIRIO), Brasil

eloise.botelho@unirio.br

\section{Carolina Todesco}

Universidade Federal do Rio Grande do Norte (UFRN),

Brasil

caroltodesco@gmail.com

Sara Pugliesi Larrabure

Universidade de Lisboa (ULisboa), Portugal, Brasil

sarapl@gmail.com
DOI: https://doi.org/10.18472/cvt.21n3.2021.1984 Redalyc: https://www.redalyc.org/articulo.oa? id $=115469516008$

\section{UM ESFORÇO EM REDE PARA COMPREENSÃO DO TURISMO EM TEMPOS DE PANDEMIA}

O dossiê que compõe esta edição do CVT traz alguns resultados do trabalho da Rede Internacional de Pesquisa Turismo em Tempos de Pandemia: uma abordagem geográfica multi e trans-escalar, sob a liderança da Profa. Dra. Rita de Cássia Ariza da Cruz (USP) e vice-liderança da Profa. Dra. Maria Goretti Tavares (UFPA). A Rede iniciou sua organização, em maio de 2020, logo após a deflagração de uma crise, sem precedentes na história, em diferentes interfaces da sociedade e, também, no turismo, devido à pandemia de Covid-19. A preocupação era deslocar o olhar de análises abrangentes e generalizantes, tais como os estudos de impactos da pandemia no setor turístico realizados pelos organismos internacionais e nacionais, e voltar-se para o lócus onde o turismo acontece, com o objetivo de compreender os desdobramentos socioeconômicos da crise nos lugares, em especial, nos que apresentam uma alta dependência dessa atividade.

Destarte, estão reunidos pesquisadores de instituições de ensino e pesquisa de diversas regiões do país, como também de instituições estrangeiras para desenvolver análises multi e trans-escalares. $\mathrm{O}$ grupo está organizado em doze equipes estaduais, oriundas do Amazonas, Pará, Maranhão, Rio Grande do Norte, Paraíba, Pernambuco, Sergipe, Rio de Janeiro, São Paulo, Mato Grosso, Mato Grosso do Sul e Paraná, e três equipes estrangeiras, formada por pesquisadores da Argentina, Portugal e Moçambique. Em 2021, mais duas equipes estrangeiras se integraram à rede, pesquisadores da Bolívia e do Paraguai.

A adesão de acadêmicos de diferentes instituições indica a relevância do tema na atual agenda de pesquisas dos estudiosos do turismo, os quais possuem grande interesse em tratar sobre os impactos da pandemia: no desemprego e na precarização das condições de trabalho no setor de turismo; nas condições de funcionamento das empresas características e da gestão pública do turismo; na competitividade e nas estratégias do mercado turístico; nas mudanças temporárias e permanentes no comportamento dos turistas; no papel do Estado no enfrentamento de crises; na mobilidade e circulação nos espaços turísticos; na reconfiguração dos fluxos turísticos; entre tantos outros. Assim, o presente dossiê apresenta três estudos que perpassam os principais temas que mobilizam o debate em torno do turismo no contexto da pandemia.

O artigo "Consequências da pandemia da Covid-19 para o setor de turismo na região Bonito/Serra da Bodoquena", de Joyce Ávila de Oliveira (IFMS), Amilton Luiz Novaes (UFGD) e Edvaldo Cesar Moretti (UFGD), tem como foco evidenciar a situação dos trabalhadores do turismo dos municípios de Bodoquena, 
Bonito e Jardim, no Mato Grosso do Sul, durante o acirramento da crise (março a setembro de 2020), e identificar a atuação e/ou negligência do poder público no amparo aos trabalhadores nesse período.

O contexto da retomada dos fluxos turísticos ainda no ano de 2020 é alvo do estudo "Pequenas e grandes cidades turísticas do Nordeste: as diferenças na retomada do turismo no cenário pandêmico", de Carolina Todesco (UFRN), Maria Aparecida Pontes da Fonseca (UFRN) e Itamara Lúcia Fonseca (UFRN). O artigo apresenta como as configuraçóes urbanas e populacionais e os casos de Covid-19 influenciaram as decisões de viagens e, consequentemente, impulsionaram uma recuperação maior do setor nas pequenas cidades comparada aos grandes centros urbanos.

Já o artigo "O turismo de Aracaju/SE em tempos de Covid-19: ameaças e tendências", de Cristiane Alcântara de Jesus Santos (UFS), Antônio Carlos Campos (UFS) e Larissa Prado Rodrigues (USP), trata sobre os impactos da pandemia nos empregos e empresas características do turismo do município de Aracaju, capital de Sergipe, assim como discute novas formas de turismo pós-Covid-19.

Os artigos que compõem esse dossiê são uma amostra qualificada de análises que permitem uma compreensão dos impactos nos lugares de uma crise global, e por isso acreditamos que sua leitura colabora com a discussão sobre o tema que permanecerá sendo alvo de muitos estudos, em virtude do aparecimento de novas variantes do vírus, que que continuam a colocar desafios para toda sociedade e para o turismo.

Ótima leitura a todos e todas! 